\title{
Incentive preference as a function of water deprivation and locus of discriminative stimuli
}

\author{
JEROME S. COHEN, ANKE OÖSTENDORP, and WILLIAM ROSS \\ University of Windsor, Windsor, Ontario, Canada N9B SP4
}

\begin{abstract}
Water-deprived rats (23.5 and $18 \mathrm{~h}$ ) acquired simultaneous discrimination tasks with position of the positive stimulus paired with water and $20 \%$ sucrose. Free-choice trials with S+ simultaneously present at both positions occurred following discrimination acquisition. Animals acquired tasks in which either goal-door and/or floor-texture cues were relevant. All moderately deprived discrimination groups displayed more errors and slower speeds to $\mathrm{S}+$ at the water than at the sucrose side. Only highly deprived animals that acquired a floor-texture discrimination developed similar, but not as great, speed differences. Such speed differences were due to increased speeds to $S+$ at the sucrose position. All but the highly deprived floor + door learners displayed reliable free-choice sucrose preferences. Moderately deprived animals tended to display greater sucrose preferences than highly deprived animals. Results were discussed in terms of attention and learning as a function of deprivation level.
\end{abstract}

Preference for sucrose solutions has been found to be a function of the type of deprivation in rats. Under free-choice conditions and limited access to reinforcement, food-deprived and/or water-satiated rats prefer increased sucrose concentrations, while water-deprived rats (22.5-23.5 h) either prefer lower concentrations or show no reliable preferences (Beck \& Bidwell, 1974; Beck \& Nash, 1969; Beck, Nash, Viernstein, \& Gordon, 1972; Beck, Self, \& Carter, 1965; Cohen \& Tokieda, 1972). With increased access to reinforcement (1 min or more per trial) or prewatering, highly deprived animals will develop sucrose preferences (Beck \& Nash, 1969; Beck et al., 1972; Cohen \& Tokieda, 1972). Cohen, Weir, and Granat (1975) demonstrated that highly water-deprived animals' preference for water over sucrose could be reversed by decreasing fixed intervals from 19 to $.25 \mathrm{sec}$ in a one-lick situation. Similar relationships have also been found, when incentives were presented separately (forced-choice condition). Fooddeprived and/or water-satiated animals typically respond (barpress) more vigorously for increased sucrose solutions, while highly water-deprived animals either respond at similar rates to all incentives (water $64 \%$ sucrose) (Beck, 1963; Oakley, 1965; Rosen \& Jacobs, 1968; Tombaugh, 1974) or develop faster rates to water (Beck \& Ellis, 1966). Highly water-deprived animals would also begin to respond more vigorously to sucrose than water at the end of lengthy experimental sessions of $30 \mathrm{~min}$ (Rosen \& Jacobs, 1968).

Cohen and Oöstendorp (1976) measured both forced-

Experiment 1 in the present study was based on a thesis submitted by the second author in partial fulfillment of the requirements for a master's degree at the University of Windsor. The present report is based on a paper delivered at the Canadian Psychological Association meeting, Quebec City, Quebec, June 1975. The authors wish to thank Dr. R.C. Beck of Wake Forest University, Winston-Salem, North Carolina, for his valuable suggestions on the manuscript. and free-choice incentive preferences (water vs $20 \%$ sucrose) in highly $(23.5 \mathrm{~h})$ and moderately $(18 \mathrm{~h})$ water-deprived animals. Animals first learned à simultaneous goal-door discrimination task in a Grice discrimination box with position of $\mathrm{S}+$ paired with incentive level (forced-choice phase). A series of freechoice trials with the S+ simultaneously available at both incentive positions followed the first phase. As predicted, only moderately deprived animals displayed consistent forced-choice preferences to sucrose as measured by errors and running speeds to $\mathrm{S}+$ at each incentive position. Contrary to expectations, however, both deprivation groups reliably preferred sucrose to water on free-choice trials $(>75 \%)$. The major question we wished to investigate was why highly deprived animals failed to display as reliable forced-choice preferences in view of their consistent free-choice sucrose preferences.

It is possible that highly deprived animals in our recent experiment were unable to modify forced-choice running speeds due to their general arousal and/or due to the possibility that they only noticed the S+ position of the doors after approaching them more closely than moderately deprived animals. Therefore, highly deprived animals may have had less time or distance to react to the incentive characteristics of each position than moderately deprived animals. The second proposition is based on Cohen and Stettner's (1968) findings that increased water deprivation decreases early anticipatory learned position responding in a modified $T$ maze. In order to test this proposition, we carried out two experiments in which a simultaneous floor-texture cue was present in the decision chamber. Such a cue, we reasoned, would allow animals to react more quickly to position of $\mathrm{S}+$ upon entering the decision chamber and, hence, allow them to modify their behavior based on the incentive characteristics of each position. It was expected that moderately deprived animals would con- 
tinue to display differential forced-choice behavior (speed and errors) regardless of the presence of the floor-texture cue. Highly deprived animals, however, were only expected to make fewer errors and run faster to $\mathrm{S}+$ at the sucrose than at the water side when floortexture stimuli either were the only discriminative attributes or were redundant and relevant with a goaldoor brightness cue. As in our previous study, a series of free-choice trials was conducted following forcedchoice trials in order to determine preferences between water and 20\% sucrose. The two experiments differed in the following ways. In Experiment 1 animals initially acquired simultaneous discrimination tasks with position of S+ of the goal door, floor texture, or both cues paired with each incentive (water and 20\% sucrose). In Experiment 2, animals first acquired the goal-door or floortexture discrimination to $10 \%$ sucrose at each position and then received an equal number of trials with $\mathrm{S}+$ position associated with each incentive.

\section{METHOD}

\section{Subjects}

Seventy male albino rats (Wistar strain) approximately 90 days old were used. Sources of animals were Woodlyn Farms, Guelph, Ontario and the breeding colony of the Psychology Department, University of Windsor. Forty-eight animals were assigned to Experiment 1 and 32 to Experiment 2. Animals were divided randomly into high- and moderate-deprivation groups in each experiment. Each deprivation group was divided randomly into three discrimination groups in Experiment 1 (floor + door, door and floor) and two in Experiment 2 (door and floor). This arrangement provided that each deprivation-discrimination group contained eight animals.

\section{Apparatus and Materials}

The same two-choice discrimination box as that used by Cohen and Oöstendorp (1976) was employed. The box consisted of a start chamber, V-shaped discrimination chamber, and two goal chambers. Running times were measured automatically in the decision chamber by photoelectric-beam relay units. Both goal-chamber doors were gray during pretraining. In subsequent phases, black and gray doors were used and removable floor panels in the decision chamber were used. These panels contained gray strips of sandpaper on either position or on both positions.

Sucrose solutions were made with tap water by weight/ volume and were refrigerated. Fresh solutions were made twice per week. All liquids were warmed to room temperature prior to each experimental session.

\section{Procedure}

Three phases were employed: pretraining, discrimination training, and free-choice testing. The pretraining procedures reported by Cohen and Oöstendorp (1976) were used. Animals learned to open goal doors for 10-sec sips of $10 \%$ sucrose in both studies while on a 21-h deprivation schedule. Following this phase, animals were divided into high $(23.5 \mathrm{~h})$ and moderate $(18 \mathrm{~h})$ water-deprivation groups and allowed to adjust to their respective deprivation schedules in their home cages for 3 days.

The same basic procedures of discrimination training and free-choice testing as described by Cohen and Oöstendorp (1976) were used. All animals received 12 experimentercorrected trials per day for 10 -sec drinks of reinforcement. Position of S+ was randomized according to Fellows' (1967) sequences. Intertrial intervals ranged from 4 to $6 \mathrm{~min}$. Acquisition criterion was two successive sessions ( 24 trials) with no more than two errors. In the first experiment, animals were required to learn either a goal-door (door group) or a floortexture (floor group) or a redundant relevant cue (floor + door group) discrimination task. The door group received simultaneous black and gray doors with the black door as S+. Both floortexture attributes (sandpaper and smooth) were present simultaneously but uncorrelated with $\mathrm{S}+$ position and, hence, irrelevant to the solution of the task. The floor-texture group received simultaneous sandpaper $(\mathrm{S}+)$ and smooth floor-texture attributes with simultaneous irrelevant door attributes. For the floor + door group, black door and sandpaper floor was S+. Only the door accompanying or containing $\mathrm{S}+$ was unlocked. Position of $\mathrm{S}+$ was paired with water and $20 \%$ sucrose. These positions remained constant throughout the course of the experiment. Incentive positions were counterbalanced for position preference during pretraining within each deprivation group. Three overtraining sessions followed achievement of the acquisition criterion. Running times to $.1 \mathrm{sec}$ were measured on errorless runs on the 2 criterion days and 3 overtraining days. Overtraining sessions were employed to obtain reliable running times to each incentive.

A free-choice preference phase followed overtraining. It consisted of three sessions in which $\mathrm{S}+$ occurred at both positions on every third trial, for a total of 12 free-choice trials in this phase. Both goal doors remained unlocked. Regular discrimination trials continued to be presented on the intertest trials. The same sequence of intertest trials as used by Cohen and Oöstendorp (1976) was used to prevent free-choice behavior from being systematically influenced by type of previous forcedchoice response.

The second experiment differed from the first study in that both deprivation groups initially acquired either door or floor discrimination tasks to $10 \%$ sucrose at both positions. Three overtraining sessions were given to obtain asymptotic speeds. Animals then received 10 sessions of forced-choice (discrimination) trials with position of S+ paired with water and $20 \%$ sucrose followed by the free-choice phase.

\section{RESULTS}

Dependent measures for the discrimination or forcedchoice phase were number of sessions to criterion, error frequency to each $\mathrm{S}+$ position, and overtraining sessions. For the first two dependent variables only individual comparisons (Newman-Keuls tests) are described, although appropriate analyses of variance were carried out. Such a summary is employed in the interests of space and because results did not depart from earlier findings (Cohen \& Oöstendorp, 1976).

In Experiment 1, highly water-deprived animals required significantly fewer sessions than moderately deprived animals to acquire their initial discriminations (seven vs eight sessions, $\mathrm{p}<.01$ ). Floor + door cue animals in that study also learned their discrimination significantly faster (six sessions) than either other discrimination group (eight sessions, $\mathrm{p}<.01$ ). Neither deprivation nor discrimination task affected acquisition rate in Experiment 2. Only moderately deprived floor or door cue groups made significantly $(\mathrm{p}<.01)$ more errors to $\mathrm{S}+$ at the water position than at the sucrose position in Experiment 1 (mean errors: 29 vs 16, door group; 32 vs 9, floor group). In Experiment 2 only moderately deprived animals made any errors to $\mathrm{S}+$ at the water side in Phase 2 (means: 14, door group; 7, floor group).

Running speeds to $\mathrm{S}+$ at each incentive position were calculated from reciprocal running time data and are 


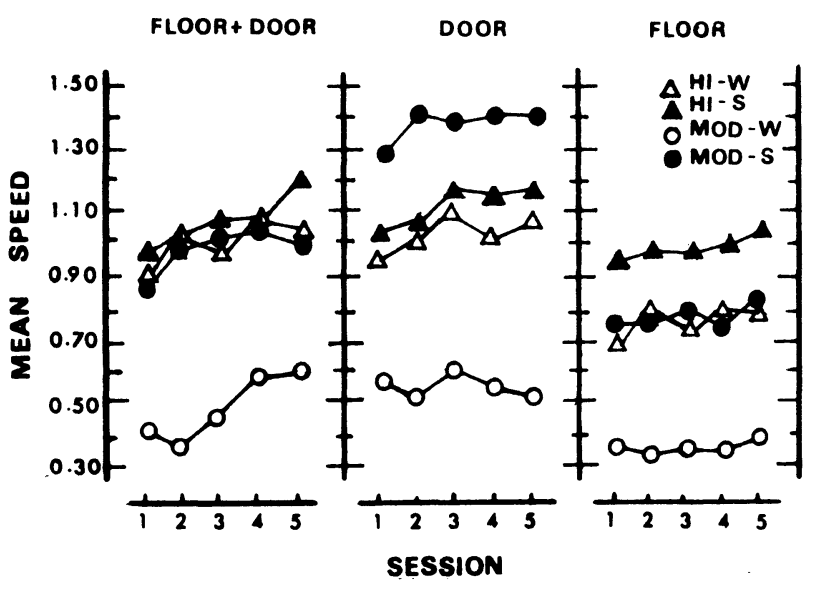

Figure 1. Mean running speeds on criterion Sessions 1 and 2 and overtraining Sessions 3-5 to each $S+$ at the water (W) and sucrose (S) positions for high (HI) and moderate (MOD) waterdeprivation groups within each discrimination task in Experiment 1.

shown in Figures 1 and 2 for Experiments 1 and 2, respectively. An analysis of incentive position was carried out in Phase 1 in Experiment 2 even though 10\% sucrose occurred at both positions. This was done to determine if any running speed differences occurred prior to differential incentive presentations (Phase 2). Although appropriate analyses of variance were carried out for each experiment, only individual comparisons based on Newman-Keuls tests and Dunnett's t tests are summarized below in the interests of space. ${ }^{1}$ In Experiment 2, a series of Dunnett's tests were used to compare changes in running speed between the last session of Phase 1 and sessions in Phase 2 in order to determine effects of incentive shifts.

First, it should be pointed out that no significant differences in speed between incentive positions or deprivation groups occurred in Phase 1, Experiment 2. Significant main effects for discrimination tasks in each experiment were due to the fact that floor animals ran more slowly than animals in the other groups $(p \leqslant .05)$. In both studies, moderately deprived animals ran significantly $(\mathrm{p} \leqslant .01)$ more quickly to $\mathrm{S}+$ at the sucrose than water side (every session, Experiment 1; from Session 3 in Phase 2, Experiment 2). Only highly deprived floor cue animals developed significantly faster speeds to $\mathrm{S}+$ at the sucrose than water side [Experiment 1: Session 1-3, $5(\mathrm{p} \leqslant .5)$; Experiment 2 : Phase 2 , Sessions 4-6 $(\mathrm{p} \leqslant .01)$, $7(\mathrm{p} \leqslant .05)$, and $10(\mathrm{p} \leqslant .01)]$. All highly water-deprived animals ran significantly $(p \leqslant .05)$ more quickly than moderately deprived animals to $\mathrm{S}+$ at the water position (every session in Experiment 1; from Session 4 for door groups and from Session 5 for floor groups in Experiment 2, Phase 2). Both groups did not significantly differ in their reaction to $\mathrm{S}+$ at the sucrose position. Only moderately deprived animals in Experiment 2 significantly reduced speeds $(p \leqslant .05)$ when incentive was shifted to water (door group: Sessions 6-10; floor group: Sessions 4, 5, 7-10). High-door animals did not significantly change speeds to shifts of incentive in either direction, but high-floor animals significantly increased speeds $(p \leqslant .05)$ to increases in sucrose (Sessions 5-7), as did moderate-door animals (Sessions $4,6,8)$.

Percent of free-choice preference to sucrose is seen in Table 1. Individual $t$ tests established that all but the high-floor + door group significantly preferred sucrose above $50 \%$ choice. Due to a lack of homogeneity of variance between groups $(\mathrm{F}=18.93, \mathrm{p}<.01)$, MannWhitney $U$ tests were used to determine differences between groups. Only in Experiment 1 did moderately deprived animals prefer sucrose significantly more than highly deprived animals within each discrimination group $(\mathrm{p} \leqslant .005)$. Indeed, significantly more moderately deprived animals chose only sucrose than highly deprived animals in Experiment $1 \quad(p<.01$, Fisher's exact-probability test). A similar but nonsignificant tendency was observed in Experiment 2.

\section{DISCUSSION}

Moderately deprived animals ran more quickly and made a) DOOR

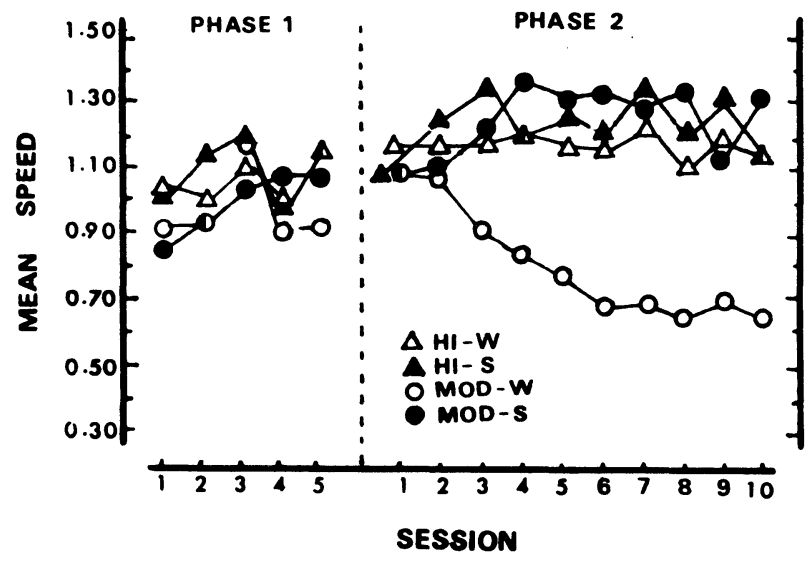

b) FLOOR

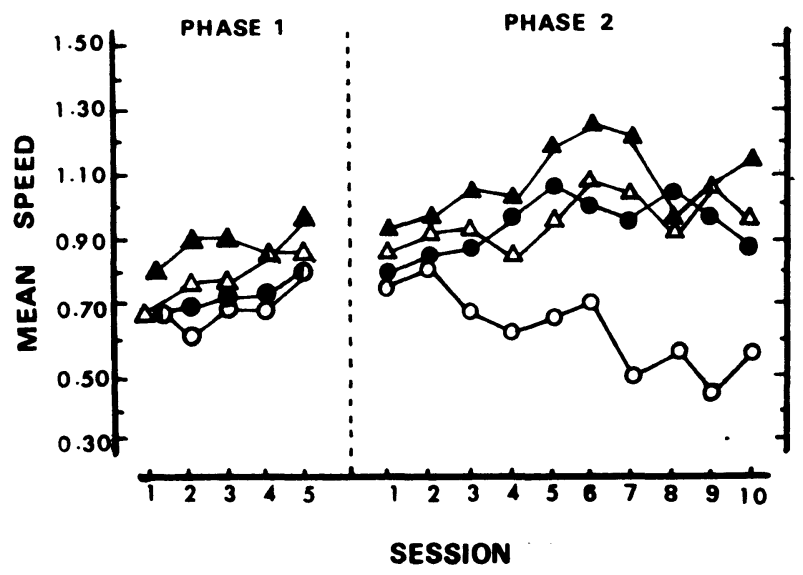

Figure 2. Mean running speeds on criterion $(1,2)$ and overtraining sessions (Phase 1) and differential incentive sessions (Phase 2) to S+ at the water (W) and sucrose (S) positions for high (HI) and moderate (MOD) groups within each discrimination task in Experiment 2 (see text for further details). 
Table 1

Proportion (P) of Sucrose Preferences and Number (N) of Animals in Each Group Only Choosing Sucrose on Free-Choice Trials in Each Experiment

\begin{tabular}{|c|c|c|c|c|c|}
\hline \multicolumn{3}{|l|}{ Experiment 1} & \multicolumn{3}{|c|}{ Experiment 2} \\
\hline & $\mathbf{P}$ & $\mathrm{N}$ & & $\mathbf{P}$ & $\mathrm{N}$ \\
\hline High Floor + Door & $.66 \dagger$ & 1 & High Door & $.74^{*}$ & 1 \\
\hline High Door & $.82^{*}$ & 4 & High Floor & $.81^{* *}$ & 3 \\
\hline High Floor & $.91 * *$ & 3 & Moderate Door & $.92 * *$ & 4 \\
\hline Moderate Floor + Door & $.99 * *$ & 7 & Moderate Floor & $.97 * *$ & 6 \\
\hline Moderate Door & $1.00 * *$ & 8 & & & \\
\hline Moderate Floor & $.99 * *$ & 7 & & & \\
\hline
\end{tabular}

fewer errors during forced-choice trials when S+ occurred at the sucrose than at the water side regardless of type of cue. As predicted, highly deprived animals developed similar speed, if not error patterns, only when $\mathrm{S}+$ was a floor-texture attribute. The mere presence of a redundant-relevant floor-texture cue with a goal-door cue was insufficient to produce such differentiated behavior, however. It would seem that, since highfloor + door cue animals ran generally as quickly as door cue animals, the former may have been only attending to the door cue. Two possible factors could account for the differentiated incentive behavior in high-floor cue animals. The immediacy of the floor cue may have allowed highly deprived animals to detect S+ position earlier than to the goal-door cue and, thus, enabled them to modify their behavior. Since floor cue groups generally ran more slowly than the other groups, as especially seen in Phase 1, Experiment 2, floor texture per se may have slowed down highly deprived animals to allow them to modify their locomotor behavior.

Forced-choice behavior also indicated that only moderately deprived animals developed conditioned inhibition to the water incentive. This was most clearly shown by a precipitous decline in running speeds and postacquisition increase of errors to water by moderately deprived animals in Experiment 2, Phase 2. Errors may be considered as an indication of avoidance responding, which is considered as a better indication of conditioned inhibition than a decline in conditioned approach behavior (Hearst, 1972). Highly deprived animals that developed differentiated locomotor behavior only did so by increasing their responding to sucrose. Therefore, highly deprived floor cue animals could be considered to have mainly developed heightened conditioned excitation to sucrose over an already high approach tendency to water.

Free-choice findings not only replicate our earlier results of reliable sucrose preferences in both deprivation groups, but also provide a possible answer to our contradictory results. A notable exception to the general pattern of results occurred within high-floor + door cue animals, which failed to develop any incentive preferences. These animals, however, acquired their discrimination more quickly than other groups and thus received less exposure to each incentive prior to free-choice testing. A careful analysis of research carried out in our laboratory and by others reveals that we generally provide more pretest exposure to each incentive condition. Therefore, increased exposure to each incentive in the form of more forced-choice trials or through increased access to reinforcement (Beck \& Nash, 1969; Beck et al., 1972) may be necessary for highly deprived animals to form sufficient incentive-position associations. Confidence in this explanation has been recently increased by Hachey's (Note 1) findings that highly water-deprived animals required twice as many forced-choice trials than moderately deprived animals to develop reliable free-choice sucrose preferences (75\%). Finally, tissue hydration as a mechanism of incentive preference in highly water-deprived rats (Cohen \& Tokieda, 1972; Cohen et al., 1975) is not applicable here due to our limited access to liquid reinforcement $(10 \mathrm{sec})$ and long intertrial intervals (4-6 min).

\section{REFERENCE NOTE}

1. Hachey, G. Incentive preference as a function of water deprivation, sucrose concentration, and amount of training. Unpublished Master's thesis, University of Windsor, 1977.

\section{REFERENCES}

BECK, R. C. Effects of variations in water need and in incentive concentration on bar pressing. Psychological Reports, 1963, 13, 31-37.

BECK, R. C., \& BIDWELl, L. D. Incentive motivational properties of sucrose and saccharine under different deprivation conditions. Motivation and Learning, 1974, 5, 328-335.

BECK, R. C., \& Ellis, V. T. Sucrose reinforcement thresholds for hungry, thirsty and nondeprived rats. Psychonomic Science, 1966, 4, 199-200.

BECK, R. C., \& NASH, R. Thirsty rats do prefer sucrose. Psychonomic Science, 1969, 15, 19-20.

Beck, R. C., Nash, R., Viernstein, L., \& Gordon, L. Sucrose preferences of hungry and thirsty rats as a function of duration of stimulus presentation. Journal of Comparative and Physiological Psychology, 1972, 48, 40-50.

Beck, R. C., Self, J. L., \& Carter, D. J. Sucrose preference thresholds for satiated and water deprived rats. Psychological Reports, 1965, 16, 901-905.

Cohen, J. S., \& Oöstendorp, A. Incentive preference under two levels of water deprivation in the rat. Bulletin of the Psychonomic Society, 1976, 8, 381-384.

Cohen, J. S., \& Stettner, L. J. Effect of deprivation level on responses to novel alleys in albino rats. Psychonomic Science, 1968, 11, 103-104.

Cohen, P. S., \& Tokieda, F. K. Sucrose-water preference reversal in the water deprived rat. Journal of Comparative and Physiological Psychology, 1972, 79, 254-258.

Cohen, P. S., Weir, J., \& Granat, M. B. Access rate as a determinant of sucrose or water preference in water deprived rats. Physiology and Behavior, 1975, 14, 383-386.

Fellows, B. Chance stimulus sequences for discrimination tasks. Psychological Bulletin, 1967, 67, 87-92.

HEARST, E. Some persistent problems in the analysis of conditioned inhibition. In R. A. Boakes \& M. S. Halliday (Eds.), Inhibition and learning. New York: Academic Press, 1972. Pp. 5-39.

OAKLEY, B. Impaired operant behavior following lesions of the thalamic taste nucleus. Journal of Comparative and Physiological Psychology, 1965, 59, 202-210.

Rosen, A. J., \& JACOBS, M. Sucrose incentive shifts in the Skinner Box with thirsty rats. Psychonomic Science, 1968, 13, 175-176.

TомваUGH, T. The interactive effects of type of deprivation and sucrose concentration on acquisition and extinction performance in the rat. Canadian Journal of Psychology, 1974, 28, 351-358.

\section{NOTE}

1. All post hoc tests were based on significant main and interaction effects in the initial analyses of variance, a summary of which will be included with each requested reprint.

(Received for publication December 3, 1976; revision accepted January $22,1977$. 